East African Medical Journal Vol. 80 No. 2 February 2003

CD4T LYMPHOCYTE SUBSETS AND DISEASE MANIFESTATION IN CHILDREN WITH AND WITHOUT HIV BORN TO HIV-1 INFECTED MOTHERS E.P. Makokha, BSc, MSc, PhD, Lecturer, Department of Immunology, Faculty of Health Sciences, Moi University, P.O. Box 4606, Eldoret, Kenya, M. Ogolla, MBChB, MMed, Catholic Relief Services, P.O. Box 48932, Nairobi, A.A. Orago, BSc, MSc, Professor, Centre for Complimentary Medicine and Biotechnology, Kenyatta University, P.O. Box 43844, Nairobi, Kenya, D.K. Koech, BSc, MSc, PhD, Chief Research Officer, S. Mpoke, BSc, PhD, Senior Research Officer, F. Esamai, MBChB, MMed, MPH, PhD, Professor, Department of Child Health and Paediatrics, Faculty of Health Sciences, Moi University, P.O. Box 4606, Eldoret, Kenya, E.M. Songok, BSc, MSc, Research Officer, N. Kobayashi, MD, Short-term Japanese Expert, F.A. Okoth, MBChB, MMed, Chief Research Officer and P.M. Tukei, MBChB, MSc, Chief Research Officer, Kenya Medical Research Institute, P.O. Box 54840, Nairobi, Kenya

Request for reprints to: Dr. E.P. Makokha, Department of Immunology, Faculty of Health Sciences, Moi University, P.O. Box 4606, Eldoret, Kenya

\title{
CD4T LYMPHOCYTE SUBSETS AND DISEASE MANIFESTATION IN CHILDREN WITH AND WITHOUT HIV BORN TO HIV-1 INFECTED MOTHERS
}

\author{
E.P. MAKOKHA, M. OGOLLA, A.S.S. ORAGO, D.K. KOECH, S. MPOKE, F. ESAMAI, \\ E.M. SONGOK, N. KOBAYASHI, F.A. OKOTH and P.M. TUKEI
}

\begin{abstract}
Objective: To understand the natural history of HIV-1 infection in children in terms of evolution of childhood clinical manifestations versus the immune status, we prospectively studied children with and without maternally transmitted HIV-1 infection born to mothers infected with HIV-1 for two years between March 1998 and March 2000. Design: A prospective cohort study.

Setting: An institutional children's home.

Subjects: Fifty nine children (26 males and 33 females) with and without maternally transmitted HIV-1 infection born to mothers infected with HIV-1 and adopted in institutional children home.

Methods: HIV-1 status of children under nine months was confirmed by polymerase chain reaction(PCR). ELISA for HIV-1 antibody in serum/plasma was used to confirm HIV-infection status for children aged $\leq 18$ months. Children were visited every three months between March and June 2000. At every visit blood was collected for total white cell count, haemoglobin and CD4+ and CD8+ $T$ cell counts. The institutional doctor routinely examined children and treated all ailments. Clinical data were recorded. Measures: HIV-DNA, anti-HIV antibodies, total white blood count, total T cell counts, CD4 and CD8 $T$ cell subset counts, frequency of childhood manifestations of infection. Results: The children were aged between 4.5 and 13 years. The baseline haematological and immunological profiles (mean, mode) were: HIV-1 sero-converters (WBC 7151,7150; HB 11.6, 12.0; CD4+ 686, 795; CD8+ 2168, 1507) and HIV-1 de-seroconverters (mean, mode) were: (WBC 8386, 7150; HB 11.7, 12.8; CD4+ 735, 795; CD8+ 2168, 1507). The commonest causes of illnesses among the HIV-1 children were URTI $(85.3 \%)$, TB(56.1\%), pneumonia $(56.2 \%)$, tonsillitis $(34.1 \%)$, parotiditis $(28 \%)$ and acute otitis media $(25 \%)$. The distribution of clinical manifestations was similar between the two categories of children, except URTI, whose prevalence was significantly increased among HIV-1 infected children (p-value=0.006). Among the HIV-1 infected children, only TB, parotiditis, and acute otitis media (AOM) were significantly associated with decreased CD4+ $T$ cell count $(\mathbf{p}<0.05)$ resulting from HIV infection.

Conclusions: HIV infection in children predisposes them to common childhood infections that can be used as markers of immune decline. TB, AOM, URTI may be early indicators of suspicion that would enable selective screening for HIV infection in children.
\end{abstract}

\section{INTRODUCTION}

HIV-1 infected children are known to suffer a myriad infections ranging from the common childhood ocular manifestations including ear, nose and throat (ENT) diseases to specific and recurrent conditions, some caused by unusual pathogens(1).

The commonest such manifestations in children infected with HIV-1, include tuberculosis(2) malnutrition(3) chronic diarrhoea(4) persistent pneumonia(5), oral candidiacies(6), failure to thrive as well as wasting and delayed mortar development(7). In Africa and particularly and outcome East Africa, most of the available reports have been focused on the rate, clinical presentation and outcome-whereby outcome is always significantly and independently associated with HIV infection $(8,9)$.

Although these studies have provided useful 
information on the spectrum of pathogens and disease manifestations in both HIV-1 infected and uninfected children(1), most of them have analysed hospital-based study cases with diverse socio-economic backgrounds, which may confound their outcome measures. Also in situations where the prevalence of disease and spectrum of pathogens are the same in both HIV infected and uninfected children, the available reports do not adequately explain the worst outcome normally associated with HIV infection(7).

The present study therefore provided us an opportunity to investigate the relationship between disease evolution, its frequency and the main immunological marker of HIV infection (CD4+ T cell) in a cohort of 52 children born to HIV-infected mothers and raised under institutional care. This was done against the background of the known relationship between HIV-1 disease progression and the host CD4+ T cell levels(10). In identifying clinical manifestations closely associated with decreased CD4+ T cell counts due to HIV-1 infection, ours was an attempt at developing a clinical algorithm for disease progression in HIV-infected children. Such an algorithm may be used as an entry point in present problematic diagnosis and management of paediatric HIV infection complicated with common childhood infections.

\section{MATERIALS AND METHODS}

Study participants: The study participants included a total of 59 children (26 males and 33 females) born to HIVseropositive mothers and accepted for adoption in a children's home at different ages following the death of their parent(s). In the orphanage, children under nine months of age had their HIV-1 status confirmed by PCR, while the HIV-1 antibody was determined by testing serum/plasma with particle agglutination and anti-HIV-1/2 antibody ELISA at age $\geq 18$ months. Reactive samples were confirmed by Western Blot (WB) assay. Of the 59 children originally enrolled into the study, 52 were confirmed to have sero-converted with antiHIV-1 antibodies, while seven sero-reverted to negative (HIV1) antibody status at different times during the course of the study. Those infected were deemed to have acquired their infection vertically. Thus the 59 children ( $52 \mathrm{HIV}+$ cases and seven HIV-controls) formed the target study sample and were followed up from March 1998 to June 2000 (for a total 27 months or until loss of follow up or death).

Clinical diagnosis and/or examination: During the entire period of the study the children home doctor (MO), routinely examined, and treated the children of all ailments. Besides routine medical care, sick children in need of further hospitalbased care were referred to designated hospitals in Nairobi.

\section{LABORATORY METHODS}

Confirmation of HIV infection status of child by polymerase chain reaction $(P C R)$ : This was done to confirm HIV infections in children aged below one year. PCR was performed on DNA samples isolated from infant peripheral blood mononuclear cells (PBMCs) using previously described methods(11). Briefly, nested PCR amplification of HIV-1 sequences was performed on DNA extracted from three consecutive PBMCs obtained from children up to nine months of age.

HIV-1 antibody testing by Enzyme immunosorbent assay (ELISA): Enzyme immunosorbent assay (ELISA) was performed according to the procedure provided by the kit manufacturers (Enzygnost HIV-1/2 ELISA, Marburg, Germany) to detect antibodies specific to HIV-1/2 in infant plasma. Detection of HIV-1/2-specific antibodies in plasma of children aged $\geq 18$ months was used to confirm the above PCR results as well as sero-conversion status of the children.

T. lymphocyte subset counts: $\mathrm{T}$ cell counts were quantitated by flow cytometry procedures using a modified standard automated immunophenotyping procedure(12). Briefly, 3-colour antibodies (pre-mixed and optimized monoclonal antibodies labelled with three different fluorochromes (anti-CD4 + PE and anti-CD8 + FITC, (Becton-Dickinson, USA) were used to stain cell surface markers. Flow cytometric acquisition and analysis were performed using FACscalubur ${ }^{\mathrm{TM}}$ cytometer using an automatic program (Multiset, Becton-Dickinson, USA).

Specimen collection: Beginning March 1998 up to June 2000 , the children were visited for sample collection every three months. At every visit $2 \mathrm{ml}$ of venous blood was collected in EDTA vacutainer tubes (Becton-Dickinson, USA) for complete blood count including haemoglobin and CD4 + T lymphocyte enumeration. At age 18 months, blood was taken from each child to confirm the HIV-1 infection status by serology.

Data collection: Baseline demographic details of each child were recorded on recruitment including age and gender. Baseline laboratory data collected included: white blood count (WBC), haemoglobin $(\mathrm{Hb})$, total $\mathrm{T}$ cell percentage (CD3+), helper T cell subset $(\mathrm{CD} 4+)$, suppressor T cell subset (CD8+), natural killer cell subset $(\mathrm{CD} 3 / \mathrm{CD} 15+56)$ and $\mathrm{B}$ cell subset $(\mathrm{CD} 19+)$. Subsequently, the above data were collected from the same children 3-monthly. At the end of the study period, clinical records of each child examined by MO were compiled for analysis in correlation with the laboratory data.

Data analysis: Data collected were managed and analysed using Statview Software ${ }^{\mathrm{TM}}$ (Abacus Concepts, Inc, Berkeley, CA USA) on Apple microcomputer. Observations on continuous and nominal variables whose underlying distribution was not normal (WBC, HB, CD4+, CD8+, etc) were computed and compared using non-parametric statistics (Mann-Whitney Utest). The Chi-square with Fishers Exact was used to compare the nominal laboratory and demographic variables recorded as well as to examine associations between these two. Also, Utests were used to test the mean difference of two nominal categories in terms of their CD4+ T cell counts. A total of 20 of the original group were lost to follow-up, thus leaving 39 children who were then consistently followed up for the present analysis.

\section{RESULTS}

Demographic characteristics of the study participants: Of the 59 children enrolled into the study, 26 were males aged (mean: 56, range: 4-120 months) and 33 were females aged (mean: 57, range: 4.5-132). 
These children had been admitted into the orphanage at different ages, normally under three years. Nine (5 females and four males) of the total 59 children desero-converted to HIV-1 negative status while the rest (30 males and 20 females) seroconverted to HIVpositive status and were thus confirmed infected. There were no significant gender differences between the HIV-1 de-seroconverters and seroconverters.

Baseline characteristics of the children: Baseline laboratory observations recorded for all the children stratified by their HIV-1 serostatus. The baseline values of haemoglobin, total white blood cell (WBC) counts and the absolute $\mathrm{T}$ cell subset counts (CD4+, CD8+) and ratios (CD4+/CD8+) were not significantly different according to their HIV-1 sero-status $(p>0.05)$ (Table 1)

CD4+ T lymphocyte subset profiles by child age: Since the decline of CD4+ T cells is considered the hallmark of HIV-1 infection, we investigated the changes of absolute CD4+ $\mathrm{T}$ cell counts during childhood infection with HIV-1. An inverse relationship between absolute CD4+ T cell levels and child age (Figure 1).

Effect of CD4+ $T$ cell levels on profiles of infections: During the study period, a total of 101 examinations/observations were recorded. At every visit a tally of clinical manifestations was made. Because HIV-1 infection is known to influence the pattern of infection, we analysed the total occurrence of every manifestation according to the mean absolute CD4+ T cell count during the study period. Table 2 is a summary of clinical manifestations observed during this study period among the children according to the mean CD4+ T cell counts. The commonest childhood causes of morbidity included URTI (88\%), TB (51\%) and various forms of pneumonia (41\%). Episodes of TB $(\mathrm{p}=0.054)$ and otitis media $(\mathrm{p}=0.056)$ were significantly more common among children with lower mean absolute CD4+ $\mathrm{T}$ cell counts over the study period than those with higher counts.

\section{Figure 1}

Bivariate scattergram with $95 \%$ confidence interval showing the decline of CD4 $\mathrm{T}$ cell count with age among HIV-1 infected children

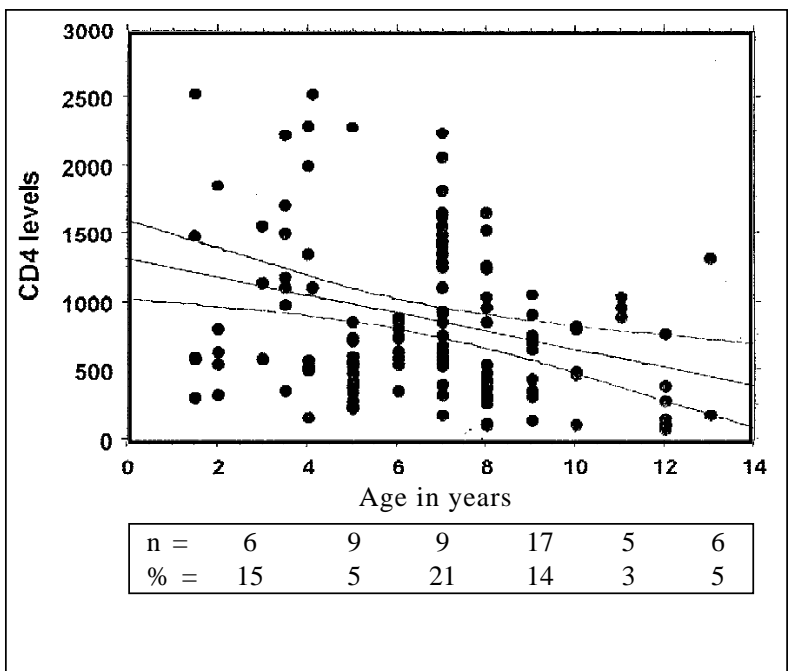

Table 1

Baseline demographic, haematological and immunological characteristics of study children stratified by HIV-1 serostatus

\begin{tabular}{|c|c|c|c|c|c|}
\hline \multirow[t]{2}{*}{ Characteristic } & \multicolumn{2}{|c|}{$\begin{array}{c}\text { HIV-sero- } \\
\text { converted } \\
\text { (Males=11, } \\
\text { Females }=19 \\
\quad(n=30)\end{array}$} & \multicolumn{2}{|c|}{$\begin{array}{c}\text { HIV-sero } \\
\text { reverted } \\
(\text { Males=4, } \\
\text { Females=5) } \\
\quad(n=9)\end{array}$} & \multirow[t]{2}{*}{ P-value } \\
\hline & Mean & Range & Mean & Range & \\
\hline Age (months) & 58.3 & 6-132 & 52 & 4-132 & 0.62 \\
\hline WBC (cells $\times 10^{3}$ ) & 7785 & $3200-15500$ & 8386 & $5600-12600$ & 0.35 \\
\hline $\mathrm{HB}(\mathrm{gm} / \mathrm{dl})$ & 11.6 & 6.3-15 & 11.9 & $8.2-14$ & 0.64 \\
\hline CD4+(cells/ $\mu \mathrm{l})$ & 686 & $107-454$ & 735 & $20-1554$ & 0.27 \\
\hline CD8+(cells/ $\mu \mathrm{l})$ & 2368 & $585-5126$ & 2161 & $1530-4543$ & 0.24 \\
\hline CD4+/CD8+ & 0.31 & $0.26-1.12$ & 0.34 & $0.25-0.78$ & 0.87 \\
\hline
\end{tabular}

Note: $\mathrm{WBC}=$ Total White Blood Cell count, $\mathrm{HB}=$ Haemoglobin level, CD4+ T (absolute CD4+ T cell subset count), CD8+ (absolute CD8+ T cell subset count), CD4+/CD8+ subset ratio. P-values were calculated by Mann-Whitney U unpaired twogroup comparison of means. 
Effect of HIV-1 sero-status on manifestations of childhood infections: We next examined whether the prevalent clinical conditions observed among the HIV1 infected group were peculiar to HIV-1 induced immunosuppression. To do this, we compared the occurrence of the same clinical manifestations in the two serological groups of children (HIV-1 sero- converters and HIV-1 de-seroconverters) (Table 3). The distributions of the commonest clinical manifestations stratified by the HIV-1 serostatus of the study children. Only URTI was significantly influenced by the HIV1 induced immunosuppression ( $\mathrm{p}=0.006$ ). These results underscore the importance of URTI in children infected with HIV-1 (Table 4).

Table 2

Relationship between clinical manifestations of children and the absolute CD4+ T cell counts during the study period among HIV infected children

Absolute CD4+ T cell count; Median (Range)

Clinical

manifestation

(\% observations or

frequency of

occurrence

$\mathrm{n} / 101 \times$ 100) during

study period

\begin{tabular}{lccc}
\hline Otitis media(29) & $622(31-2065)$ & $952(107-2524)$ & 0.047 \\
Parotidis(30) & $540(31-2540)$ & $803(105-2290)$ & NS \\
Pneumonia(41) & $745(109-2224)$ & $702(31-2243)$ & NS \\
URTI(88) & $738(31-2290)$ & $803(148-2524)$ & NS \\
Tuberculosis(51) & $601(105-2224)$ & $885(31-2524)$ & 0.030 \\
Tonsilitis(36) & $906(105-2224)$ & $709(105-2524)$ & NS \\
Malaria(9) & $731(698-800)$ & $841(801-875)$ & NS \\
Ulcers/Boils(11) & $760(31-2524)$ & $667(154-2005)$ & ND \\
Herpes zooster(0) & $818(630-997)$ & $776(645-806)$ & NS \\
Epilepsy(4) & $746(351-2504)$ & $761(31-2290)$ & NS \\
Dermatitis(6) & $577(138-858)$ & $746(31-2243)$ & NS \\
Conjuctivitis(1) & $686(405-2243)$ & $738(31-2224)$ & NS \\
Cardiomegally(3) & $871(871-887)$ & $727(31-2243)$ & NS \\
Chicken pox(2) & $1344(1182-1506)$ & $1287(986-1330)$ & \\
\hline
\end{tabular}

Note: URTI = Upper respiratory tract infections. P-value was calculated using Fisher's exact test comparing the levels of CD4+ T cell counts between HIV-coinfected with a particular infection and those without infection assuming no association between the two categories. Significance level was taken as $\mathrm{p} \leq 0.05$ i.e. NS $=$ Not significant.

Table 3

Clinical manifestations exhibited by the study children during the study period according to their HIV-1 conversion status

\begin{tabular}{|c|c|c|c|c|}
\hline \multirow[b]{2}{*}{ Infection } & \multicolumn{3}{|c|}{ Frequency of infections, n (\%) } & \multirow[b]{2}{*}{ P-value } \\
\hline & Infection status & $\begin{array}{c}\text { Among HIV- } \\
\text { seroconverted }(n=41)\end{array}$ & $\begin{array}{l}\text { Among HIV- } \\
\text { de-seroconverted }(n=9)\end{array}$ & \\
\hline \multirow[t]{2}{*}{ URTI } & YES & $35(85.3)$ & $1(20)$ & \multirow{3}{*}{0.006} \\
\hline & NO & $6(14.6)$ & $4(80)$ & \\
\hline \multirow[t]{2}{*}{ Acute-Otitis media } & YES & $13(31.7)$ & $1(20)$ & \\
\hline & NO & $28(68.3)$ & $4(80)$ & \multirow[t]{2}{*}{ NS } \\
\hline \multirow[t]{2}{*}{ Tuberculosis } & YES & $23(56.1)$ & $1(20)$ & \\
\hline & NO & $18(43.9)$ & $4(80)$ & \multirow[t]{2}{*}{ NS } \\
\hline \multirow[t]{2}{*}{ Pneumonia } & YES & $18(56.2)$ & $0(0)$ & \\
\hline & NO & $14(43.8)$ & $5(100)$ & \multirow[t]{2}{*}{ NS } \\
\hline \multirow[t]{2}{*}{ Tonsilitis } & YES & $14(34.1)$ & $1(20)$ & \\
\hline & NO & $27(65.9)$ & $4(80)$ & \multirow[t]{2}{*}{ NS } \\
\hline \multirow[t]{2}{*}{ Malaria } & YES & $8(19.5)$ & $0(0)$ & \\
\hline & NO & $33(80.5)$ & $5(100)$ & NS \\
\hline
\end{tabular}


Table 4

Clinical manifestations stratified by HIV-1 seropositive and seronegative status of children

\begin{tabular}{lccc}
\hline \multicolumn{4}{c}{ Children HIV status } \\
\multicolumn{5}{c}{ HIV+(n=41) } & HIV-(n=5) & $\begin{array}{c}\text { Fisher's exact } \\
\text { p-value }\end{array}$ \\
\hline Infection & No. (\%) & No. (\%) & \\
\hline URTI & & \\
Yes & $35(85.3)$ & $1(20)$ & \\
No & $6(14.6)$ & $4(80)$ & 0.0057 \\
Acute otitis media & & \\
Yes & $13(31.7)$ & $1(20)$ & $>0.999$ \\
No & $28(68.3)$ & $4(80)$ & \\
Tuberculosis & & & \\
Yes & $23(56.1)$ & $1(20)$ & \\
No & $18(43.9)$ & $4(80)$ & \\
Pneumonia & & & \\
Yes & $18(56.2)$ & $0(0)$ & \\
No & $14(43.8)$ & $5(100)$ & 0.454 \\
Tonsilitis & & & \\
Yes & $14(34.1)$ & $1(20)$ & 0.66 \\
No & $27(65.9)$ & $4(80)$ & \\
Malaria & & & \\
Yes & $8(19.5)$ & $0(0)$ & \\
No & $33(80.5)$ & $5(100)$ & \\
\hline
\end{tabular}

\section{DISCUSSION}

The decline in the number of $\mathrm{CD} 4+\mathrm{T}$ cells is considered as one of the most reliable laboratory markers of disease severity in subjects (adults and children) with HIV infection and is also used as a predictor of disease progression(14). However, in children with perinatally acquired HIV infection, the role of cell-mediated immune response and disease progression are not as well defined as in adults(15). In this study therefore, we tried to relate the longitudinal clinical spectrum of HIV-1 -associated conditions to the CD4+ $\mathrm{T}$ cell count as a marker of immune deficiency in children drawn from the same socio-economic background in Nairobi, Kenya. We first analysed the profile of $\mathrm{T}$ cell decline with age of children. Our results show a progressive decline of CD4+ $\mathrm{T}$ cell counts towards adult levels observed during early HIV infection, despite different ages of enrollment into the study. This implies that the measurement of CD4+ $\mathrm{T}$ cells could be useful both in the diagnosis and prognosis of HIV infection in individual children. We did not, however, analyse the evolution of various infections with the exact timing of CD4+ lymphocyte decline. If this had been done, it would help define progression of disease in terms of opportunistic infections in children. It would also help define the probability of progression according to the decline of CD4+ lymphocyte count. Although our failure to do this may constraint the applications of these laboratory data, our results, however, do confirm previous findings that the levels of CD4+ T lymphocytes in HIV infected children decline progressively with age but remain higher than in adults(16). We further acknowledge the limitations posed by the small sample size of our study cohort. This meant that insufficient information was available to correlate CD4+ T cell levels with disease occurrence at all age groups. However, even with such a small sample size, our results clearly show that low age-specific CD4+T cell counts were correlated with conditions associated with immunosuppression in the study children.

In this study group, childhood illnesses that occurred commonly and with a similar prevalence in HIV-infected and HIV-exposed but uninfected children included: URTI, pneumonia, and tuberculosis, parotid swellings, acute otitis media, tonsillitis, persistent diarrhoea and skin ulcers. However, only TB, parotiditis and AOM could be considered as indicators of HIV- infection since their prevalence was significantly correlated with decreased CD4+ $\mathrm{T}$ cell resulting from HIV infection. Despite the small sample size used in this study, our findings are in agreement with reports from Nigeria(17), South Africa(18) and Sudan(19) which observed a wide range of clinical manifestations in HIV-infected children. In this study, however, only TB, parotiditis and AOM were identified as indicator opportunistic infections in children infected with HIV-1. This narrow range of clinical manifestations observed may partly be explained by the small sample size observed and more importantly by the fact that the study cases were drawn from a wellnourished group of children living in an institutional childrens' home. Although URTI was the most prevalent clinical manifestation in this cohort, it was not significantly associated with levels of CD4+ T cells. Interestingly, it was the commonest cause of morbidity among HIV-1 infected children $(p=0.006)$. This suggests that URTI is an important clinical presentation in HIV-infection in childhood but whose manifestation is independent of CD4+ $\mathrm{T}$ cells.

AOM and/or parotiditis were significantly prevalent in children with lower CD4+ T cell counts than those with higher. In this respect, our results agree with previous studies which have not only reported a higher occurrence of AOM and other otorhinolaryngological manifestations in HIV infected children(20) but also a rapid and significant $\mathrm{HIV}$-disease progression in correlation with AOM in children(21). From these findings, we suggest that the treatment for AOM in children take cognizance of the possibility of unusual pathogens taking advantage of immunosuppression to cause severe complications in children infected with HIV-1. We further suggest that a renewed emphasis be put on the prevention and treatment of such opportunistic infections before complications set in.

Regarding TB, children infected with HIV-1 have been reported to have higher episodes of persistent and chronic lung disease whose cause is suspected to be Mycobacterium tuberculosis(22). In this study, children with a lower mean CD4+ $\mathrm{T}$ cell count had a significantly 
higher prevalence of TB than those with higher counts. This agrees with available reports on TB and HIV coinfections being more likely to have decreased CD4+T cells than other-age-matched HIV-infected children(23). In this region, however, childhood TB, especially when compounded by HIV-1 infection is still associated with problems of proper diagnosis and treatment. Therefore, identification of TB as an early indicator of suspicion and hence selective screening for HIV infection based on decreased CD4+ T cell count may be a useful clinical algorithm for HIV-disease progression in children. This is because, HIV-infected children are known to be at a higher risk of pulmonary TB than uninfected ones and are also significantly poorer responders to TB treatment leading to higher losts-to-follow up rates than uninfected children(24). Thus our findings underscore the need for further investigation of larger cohorts of children coinfected with HIV and TB. At present, diagnosis and management of childhood infections in a resource-poor setting like ours is in dilemna: should TB chemoprophylaxis precede antiretroviral therapy or wait until HIV is diagnosed? On the other hand, should children with pulmonary illness be tested for TB, and should children with TB be tested for HIV?

\section{ACKNOWLEDGEMENTS}

This work was supported by the Japan International Co-operation Agency (JICA) through the KEMRI/JICA HIV/AIDS Collaborative project and the Moi UniversityMHO/Nuffic (Nertherlands) collaborative Program. The authors thank the Cottolengo Children Home, Nairobi, director KEMRI for all the clinical and laboratory work-up, Prof. Y. Fujiyama, Dr K. Kakimoto and Dr Y. Suguira of JICA for their technological assistance and computer informatics, colleagues and friends in the immunology and P2/3 laboratories of KEMRI.

\section{REFERENCES}

1. Taha, T.E., Graham, S.K., Kumwenda, N.I., et al. Morbidity among HIV-A infected and uninfected African children. Paediatrics. 2002; 106:E77.

2. Madhi, S.A., Huebner, R.E., Doedens, L., et al. HIV-1 coinfection in children hospitalized with tuberculosis in South Africa. Int. J. Tuberc. \& Lung Dis. 2000; 45:448-454.

3. Ball, C.S. Global issues in paediatric nutrition. Nutrition 1998; 14:767-770.

4. Johnshon, S., Hendson, W., Crewe-Brown, et al. Effect of human immunodeficiency virus infection episodes of diarrhea among children in South Africa. Pediat. Infect. Dis. J. 2000; 19:972-979.

5. Zar, H.J., Hanslo, D., Tannenbaum, et al. Aetiology and outcome of pneumonia in human immunodeficiency virusinfected children hospitalized in South Africa. Acta. Paediat. 2001; 90:119-125.

6. Santos, L.C., Castro, G.F., de Souza, I.P. and Oliveira, R.H. Oral manifestations related to immunosuppression degree in HIV positive children. Braz. Dental J. 2001; 12:135138.

7. Spira, R., Lepage, P., Msellati, P., et al. Natural history of human immunodeficiency virus type 1 infection in children: a five year prospective study in Rwanda. MTCT of HIV-1 Transmission Study Group. Paediatrics 1999; 104:56.

8. Resino, S., Gurbindo, D., Cano, J.M., Sanchez-Ramon, S. and Muoz-Fernandez, M.A. Predictive markers of clinical outcome in vertically HIV-1 infected infants. A prospective longitudinal study. Pediat. Res. 2000; 47:509.

9. Muhe, L. A four-year cohort study of HIV seropositive Ethiopian infants and children: clinical course and disease patterns. Ethiop. Med. J. 1997; 35:103-115.

10. Kawo, G., Karlsson, K., Lyamuya, E., et al. Prevalence of HIV type 1 infection, associated clinical features and mortality among hospitalized children in Dar es Salaam, Tanzania, Scand J. Infect Dis 2000; 32:357-363.

11. Embree, J., Bwayo, J., Nagelkerker, N. et al . Lymphocyte subsets in human immunodeficiency virus type 1 -infected and uninfected children in Nairobi. Pediat. Infect. Dis. J. 2001; 20:397-403.

12. Rogers, M.F., Ou C.Y., Rayfield, M., et al. Use of the polymerase chain reaction for early detection of proviral sequences of human immunodeficiency virus in infants born to seropositive mothers. N. Eng. J. Med. 1989; 320:1649-1654.

13. CDC. Revised guidelines for performing CD4+ $\mathrm{T}$ cell determinations in persons infected with human immunodefieciency virus (HIV). MMWR 46(RR-2):1-29.

14. Aldous, M.C., Raab, G.M., Mok, J.Y., et al. CD4 and CD8 lymphocytes in diagnosis and disease progression pf paediatric HIV infection. Pediatr AIDS HIV Infect 1996; 7:20-30.

15. Wasik, T.J., Wierzibicki, A., Whiteman, V.E., Trinchieri, G., Lischer, H.W. and Kozibar, D. Association between HIV-specific $\mathrm{T}$ helper and CTL activities in paediatric AIDS. Eur. J. Immunol. 2000; 30:117-127.

16. Rich, K.C., Brambilla, D., Landay, A. Lymphocyte phenotyping in infants: maturation of lymphocyte subpopulation and effects of HIV infection. Clin. Immunopathol. 1997; 85:273-281.

17. Akpede, G.O., Ambe, J.P., Rabasa, A.I., et al. Presentation and outcome of HIV-1 infection in hospitalized infants and other children in north-eastern Nigeria. East Afr. Med. J. 1997; 74:21-27.

18. Jeena, P.M., Pillay, P., Pillay, T. and Coovadia, H.M. Impact of HIV-1 co-infection on presentation and hospitalrelated mortality in children with culture proven pulmonary tuberculosis in Durban, South Africa. Int. J. Tuberc. Lung Dis. 2002; 6:672-678.

19. Hashim, M.S., Salih, M.A., EI Hag, A.A., et al AIDS and HIV infection in Sudanese children. A clinical and epidemiological study. AIDS Patient Care \& STDs. 1997; 11:331-337.

20. Padhani, D.H., Manji, K.P. and Mtanda, A.T. Ocular manifestations in children with HIV infection in Dar es Salaam, Tanzania. J. Trop. Pediatr. 2000; 46:646-648.

21. Godim, L.A., Zonta, R.F., Fortuamp, E. and Schmeling, R.O. Otorhinolaryngological manifestations in children with human immunodeficiency virus infection. Int. J. Paediat. Otorhinolaryngol. 2000; 54:97-102.

22. Jeena, P.M., Coovadia, H.M., Thula, S.A., Blythe, D., Buckels, N.J. and Chetty R. Persistent and chronic lung disease in HIV-1 infected and uninfected African children. AIDS 1998; 12:1185-1193.

23. Mukadi, Y.D., Wiktor, S.Z., Coulibaly, I.M., et al. Impact of HIV infection on the development, clinical presentation and outcome of tuberculosis among children in Abidjan, Cote d'Voire. AIDS 1997; 11:1151-1158.

24. Kiwanulka, J., Graham, S.M., Coulter, J.B., et al. Diagnosis of pulmonary tuberculosis in children in an HIV-endemic area, Malawi. Annals Trop. Paediat. 2001; 21:5-14. 